\title{
Adoption of e-health technology by physicians: a scoping review
}

This article was published in the following Dove Press journal:

Journal of Multidisciplinary Healthcare

I August 2016

Number of times this article has been viewed

\author{
Chloe de Grood' \\ Aida Raissi ${ }^{2}$ \\ Yoojin Kwon ${ }^{3}$ \\ Maria Jose Santana' \\ 'Department of Community Health \\ Sciences, W2IC Research and \\ Innovation Centre, University of \\ Calgary, Calgary, ${ }^{2}$ University of \\ Alberta, Edmonton, $\mathrm{AB},{ }^{3}$ Toronto \\ Public Library, Toronto, ON, Canada
}

Correspondence: Maria Jose Santana O'Brien Institute for Public Health, Cumming School of Medicine, University of Calgary, 3rd Floor TRW Building, 3280 Hospital Drive Northwest, Calgary, AB,

T2N 4Z6, Canada

Tel + I 4032109257

Fax +I 4032109850

Email mjsantan@ucalgary.ca
Objective: The goal of this scoping review was to summarize the current literature identifying barriers and opportunities that facilitate adoption of e-health technology by physicians.

Design: Scoping review.

Setting: MEDLINE, EMBASE, and PsycINFO databases as provided by Ovid were searched from their inception to July 2015. Studies captured by the search strategy were screened by two reviewers and included if the focus was on barriers and facilitators of e-health technology adoption by physicians.

Results: Full-text screening yielded 74 studies to be included in the scoping review. Within those studies, eleven themes were identified, including cost and liability issues, unwillingness to use e-health technology, and training and support.

Conclusion: Cost and liability issues, unwillingness to use e-health technology, and training and support were the most frequently mentioned barriers and facilitators to the adoption of e-health technology. Government-level payment incentives and privacy laws to protect health information may be the key to overcome cost and liability issues. The adoption of e-health technology may be facilitated by tailoring to the individual physician's knowledge of the e-health technology and the use of follow-up sessions for physicians and on-site experts to support their use of the e-health technology. To ensure the effective uptake of e-health technologies, physician perspectives need to be considered in creating an environment that enables the adoption of e-health strategies.

Keywords: medical informatics, electronic medical records, diffusion of innovation, attitude of health personnel, information seeking behavior

\section{Background}

Health care systems face challenges delivering care across the continuum, specifically for the aging population with complex chronic conditions. Health information technology, particularly information and communication technology, presents a solution to address these challenges ${ }^{1,2}$ by providing ways to increase health service effectiveness and improve patient outcomes and health care delivery. ${ }^{1,2}$ For instance, electronic medical records (EMRs) have been shown to significantly reduce the occurrence of medication errors; ${ }^{3}$ prescription errors and compliance by patients to medication regimes have been shown to improve with electronic prescribing. ${ }^{4}$ In addition, point-of-care decision support tools enable health care providers to receive alerts for contraindicated medications instantaneously. ${ }^{5}$ Furthermore, there is evidence that e-health systems have resulted in fewer hospital visits and cost savings to the health care system. ${ }^{6}$ In particular, this communication tool was used by elderly people at home to receive advice from nurses, saving visits to the clinics (emergency and elective). 
This positive evidence has supported the implementation of e-health technology across the globe, ensuring the commitment of governments such as the US and a number of countries in Europe to allocate a significant amount of resources to promote e-health technology. Examples include the implementation of EMR by $29 \%$ and $17 \%$ of primary care physicians in the European Union and the US, respectively $^{7}$ and $\$ 19$ billion committed to the promotion of health care information technology by the American Recovery and Reinvestment Act 2009. ${ }^{8}$

However, despite the high investment on e-health technology by health care systems, the evidence of the effects of e-health benefits is still very poor. In some instances, the lack of systems structures (eg, integration of e-health systems) presents a barrier to the adoption of the new technology, while in other cases it can be harmful. For instance, recent studies developed and implemented an e-health communication tool to transfer patient summary of stay in hospital from acute to community-based physicians, assessing the experiences of both group of physicians. ${ }^{910}$ This study revealed that although the e-health communication tool was well received, the adoption of the new technology was very slow. ${ }^{10}$

Furthermore, an example of the latter is the study conducted by Lupianez-Villanueva et $\mathrm{l}^{11}$ who argue that there can be a disconnect between the proposed benefits and the actual outcomes of e-health technology. The Web 2.0 described in their study has been suggested as a way to improve social interaction in health care; however, it did not foster communication between patients and doctors. ${ }^{11}$ This study indicates that the effects of e-health technology are not always positive and the benefits of their use are not always straightforward.

Clearly, there are differences in the effects of e-health technologies that depend on the type and situation of the technology; however, implementation of such technologies continues, sometimes with support from government in both deployment and promotion.

Nowadays, despite studies indicating the benefits from certain kinds of e-health technology and the interest from policy makers to implement the innovative technology, the uptake and adoption of e-health technologies has not always been consistent within health care practice, and adoption of these technologies has lagged behind. ${ }^{12}$ Physicians' acceptance of e-health technology is critical, and thus it is important to identify influences that lag the uptake in order to overcome it.

The objective of this scoping review is to identify and summarize the current literature identifying barriers and opportunities that facilitate and hinder the adoption and implementation processes of e-health technology by physicians.

\section{Methods}

To identify relevant references the following databases were searched electronically since their inception to July 24, 2015: Ovid MEDLINE, including in-process and other nonindexed citations; Ovid EMBASE; and Ovid PsycINFO. In an attempt to track gray literature, Google Scholar was used. The search strategy used for searching MEDLINE is provided as an example (Supplementary materials). It was modified according to the indexing systems of other databases. As shown in the supplementary materials, selected subject headings and keywords were searched on physicians, e-health technology, and physicians' attitudes. No language restrictions or publication date range limits were applied. In addition, we also scanned reference lists from retrieved articles and journals to identify additional studies for this review. The scoping review methodology will be guided by recommendations published in Arskey and O'Malley's methodological framework. ${ }^{13}$

\section{Inclusion and exclusion criteria} Inclusion

Studies that focus on barriers and opportunities of e-health technology adoption and implementation by physicians were included in this scoping review.

\section{Exclusion}

Studies were excluded if they met the following criteria:

- Studies in which barriers or opportunities for the adoptions of e-health technology were not described

- Barriers or opportunities for adoption of e-health technology were described for nonphysician health care providers

- Overview of the literature for the purpose of theory building

- An overview of the literature for the purpose of an editorial

- Editorials

This scoping review focused on nonrandomized studies due to the nature of the objectives of the study. Nonrandomized studies include nonrandomized controlled trials, controlled before-and-after studies, prospective cohort studies, retrospective cohort studies, case-control studies, and cross-sectional studies.

\section{Study selection}

Two investigators independently reviewed the titles and abstracts of all applicable studies from the initial search and identified those that met the inclusion criteria. Studies that were not relevant and nonprimary data were excluded in the 
screening of titles and abstracts. Discrepancy was resolved through discussion and consensus. Kappa statistics were used to assess the level of agreement between the two reviewers.

\section{Data extraction and analysis}

Textual descriptions and data tables were used to organize information concerning extracted data by the two reviewers (authors CD and AR). The results were synthesized through a detailed description of characteristics and findings of the included studies. Tables were used to present counts and percentages, details regarding study design, intervention, duration of intervention, outcome of interest, results, and study quality. A narrative synthesis was conducted to provide an overall picture of the available information. Within this narrative synthesis, patterns or "themes" were identified and aggregated together. This process involved the authors familiarizing themselves with the data, generating codes, identifying themes within the codes, and naming the themes.

\section{Results}

\section{Identification and inclusion of studies}

The search strategy yielded a total of 9,428 articles as shown in Figure $1 .{ }^{14}$ With the screening of titles and abstracts, a kappa score of 0.93 was obtained and 154 articles remained to be reviewed in full detail. Following full-text review, 80 articles were excluded mainly for including barriers or opportunities to adoption of e-health technology for nonphysician health care providers and lacked barriers or opportunities for implementation of e-health technology as a main objective in the study. Seventy-four studies were included in this scoping review.

More than half of the studies (62.2\%) included originated from North America (Table 1). The included studies used quantitative methods (54.1\%) to determine barriers and facilitators contributing to the adoption of e-health technology (Table 1 and supplementary materials). Qualitative studies (32.4\%) that were included provided structured and in-depth information regarding barriers and facilitators contributing to the adoption of e-health technology (Table 1 and supplementary materials). These studies utilized a number of designs including semi-structured interviews with physicians either in person or by phone and focus groups. The remainders of the studies were systematic reviews, mixed methods, and literature reviews. EMRs or electronic health records and telemedicine were studied in $47.3 \%$ and $13.5 \%$ of the included studies, respectively, and they were the most common types of e-health technologies assessed (Table 1 and supplementary materials).

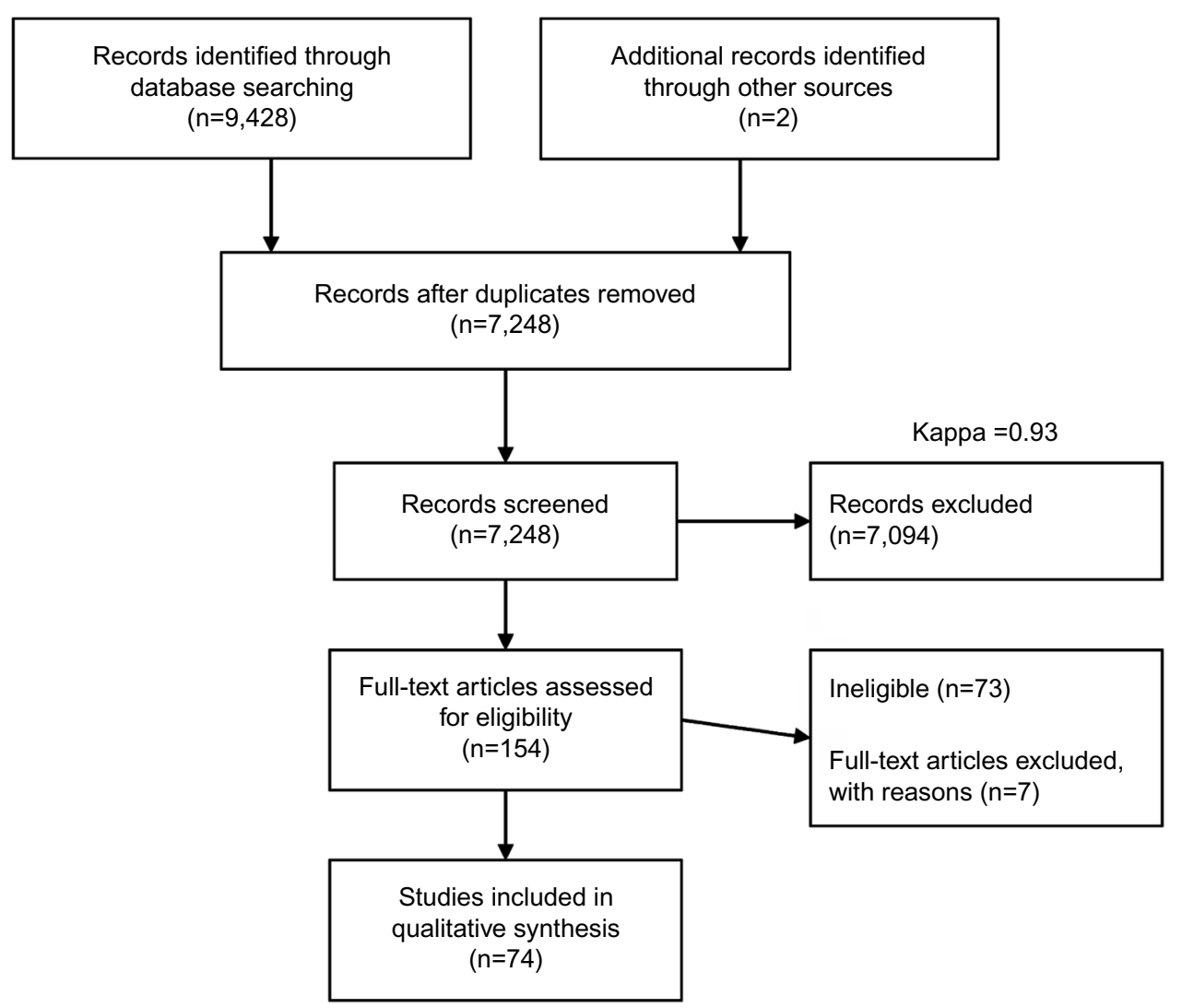

Figure I Flow diagram for the selection of studies included in the qualitative synthesis. 


\section{Outcomes assessed}

The outcomes we examined from studies included in the review were the satisfaction level of physicians, impact of the new e-health technology on the relationship between professionals and respective patients, impact of the new e-health technology on the relationship between health care professionals, the level of skill required for the implementation of the new e-health technology, and the level of complexity of the new e-health technology.

\section{Barriers and perceived facilitators}

Barriers and facilitators to the adoption and implementation of e-health technologies from the 74 studies were sorted into common theme groups identified in the review.

\section{Barriers}

\section{Design and technical concerns}

Two subthemes were identified:

Lack of harmonization of e-health systems: A notable barrier to the adoption of e-health technology is the development of a system that is not compatible with existing systems, although system integration was considered to be very important to physicians. ${ }^{15-27}$

Usability issues: Physicians expressed the importance of developing e-health technology that is simple to use, with physicians using terms such as "user friendly" and "intuitive". ${ }^{15,17,20,22,23,25,28-37}$ As one physician stated, "lots of features were available in the system, but it was always very difficult for me to find the features at the time when I needed them". ${ }^{27}$

\section{Privacy and security concerns}

Confidentiality ${ }^{15,32,38-40}$ and privacy ${ }^{19,27,32,39,41,42}$ were reported as important concerns for physicians. As one physician pointed out, "some patients do not want to share their medical records because of the sensitive health data such as HIV test information". ${ }^{27}$ Physicians were concerned that the integration of e-health technology into current systems may compromise the confidentiality of health data. ${ }^{15,28}$ Existence of health care professional codes of conduct and informed consent from patients were listed as protective factors against confidentiality concerns. ${ }^{15}$ Privacy concerns were centered on the fear that e-health technology may attract "hackers". ${ }^{32}$ Furthermore, physicians feared that e-health technology would be implemented imperfectly, allowing for security vulnerabilities. ${ }^{32}$

\section{Cost and liability issues}

Physicians were also less willing to use e-health technology if rules surrounding reimbursement ${ }^{15,23-25,27,38-41,43-55-57}$ and
Table I General characteristics of studies included in the review $(\mathrm{n}=74)$

\begin{tabular}{|c|c|c|}
\hline Characteristics & $\begin{array}{l}\text { Number } \\
(n=74)\end{array}$ & $\begin{array}{l}\text { Percentage } \\
\text { (\%) }\end{array}$ \\
\hline \multicolumn{3}{|l|}{ Country/region of origin } \\
\hline North America & 46 & 62.2 \\
\hline Europe & 10 & 13.5 \\
\hline Asia & 7 & 9.5 \\
\hline Australia & 5 & 6.7 \\
\hline North America/Europe & $\mathrm{I}$ & 1.4 \\
\hline Not specified & 5 & 6.7 \\
\hline \multicolumn{3}{|l|}{ Year published } \\
\hline $2012-2015$ & 34 & 46.0 \\
\hline $2008-2011$ & 26 & 35.1 \\
\hline 2004-2007 & 8 & 10.8 \\
\hline 1999-2003 & 4 & 5.4 \\
\hline $1995-1998$ & 2 & 2.7 \\
\hline \multicolumn{3}{|l|}{ Methodology } \\
\hline Qualitative & 24 & 32.4 \\
\hline Quantitative & 40 & 54.1 \\
\hline Mixed methods & 4 & 5.4 \\
\hline Systematic review & 4 & 5.4 \\
\hline Literature review & 2 & 2.7 \\
\hline \multicolumn{3}{|l|}{ e-Health technology } \\
\hline EMR or EHR & 35 & 47.3 \\
\hline Telemedicine & 9 & 12.2 \\
\hline e-Prescribing & 7 & 9.5 \\
\hline General e-health/HIT & 6 & 8.1 \\
\hline Health knowledge management ${ }^{\mathrm{a}}$ & 4 & 5.4 \\
\hline CPOE & 3 & 4.1 \\
\hline mHealth & 2 & 2.7 \\
\hline Other $^{b}$ & 8 & 10.8 \\
\hline
\end{tabular}

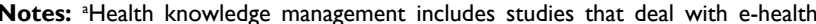
and use of evidence-based or best practice. ' Other e-health technologies include e-referral, remote monitoring technologies, a clinical information system, health information system, shared care software, electronic transfer of care tool, electronic decision support, and educational email alerts.

Abbreviations: EMR, electronic medical record; EHR, electronic health record; HIT, health information technology; CPOE, computerized physician order entry.

liability were not determined in advance. ${ }^{38,43,48}$ Physicians wondered how the expenses associated with maintaining e-health devices would be covered. ${ }^{20,40,43,44,49,50,53,54,58}$ It was expressed that financial incentives would encourage physicians to adopt e-health systems and take on additional workload. ${ }^{15}$ Some physicians, on the other hand, were very concerned with medical malpractice suits that may arise from deferring tests based on health information obtained from telemedicine. ${ }^{16,47,53}$

\section{Productivity}

Physicians expressed concern over loss of productivity during the implementation process of e-health technology. ${ }^{41,45,46}$ Post implementation, physicians were also concerned that productivity would be decreased with increased work of documentation and difficulties associated with using systems or devices that may not be user-friendly. ${ }^{46,49,50,54,59,60}$ 


\section{Patient and physician interaction}

Physicians stated concerns regarding the loss of contact between patient and the physician with the utilization of telemedicine device. ${ }^{19,23,26,27,30,43,53,57,58}$ As one physician summarized, "I found it (e-health technology) quite fiddly and complicated and spent too much time in the consult with the computer rather than talking to the family". However, if it was perceived that patients liked their physicians utilizing e-health technology, physicians were more likely to use e-health technology ${ }^{61}$ Other studies found that e-health technologies are likely to integrate delivery of health care allowing for self-management and mutual respect between the patient and physician. ${ }^{15}$

\section{Lack of time and workload}

Studies have cited lack of time and workload experienced by physicians as other key barriers to the implementation of e-health technology. ${ }^{19,24,32,33,38,41,42,48,51,55,58,62-64}$ More specifically, there were concerns expressed about the time required to implement and acquire the necessary skills to learn e-health technology. Some believed that e-health technology would demand time away from their clinical tasks. Therefore, some physicians attributed successful use of e-health technology to personal initiative. ${ }^{31}$ Others found that smaller practices were less likely to adopt e-health technology due to the lack of support. ${ }^{58}$ Another common concern was the volume of information generated by e-health technology. Physicians were concerned that they would not be able to effectively synthesize and address the large volumes of data. ${ }^{15,43}$ Other physicians were concerned that e-health technology might shift workload onto them..$^{18,32,60}$

\section{Threatened clinical autonomy}

Some physicians expressed thoughts that certain physicians would not be willing to change their practice patterns and use telemedicine devices. ${ }^{16,28,38-41,43,47,65-68}$ This may be due to the physicians' desire to form their own clinical decisions without the "bias" that may be introduced by e-health technology. ${ }^{16}$ Or, in some cases, some physicians simply feared change. ${ }^{66}$ Other studies have shown that older physicians are less likely to adopt and utilize EMR systems. ${ }^{58,68}$ Other physicians were concerned that the information generated by e-health technology, specifically health information exchange, may "flaw the logical process of their decision making" by formulating a diagnosis prior to assessing the patient. ${ }^{16}$ Unwillingness to adopt e-health technology was the major reason behind the perceived threatened clinical autonomy. ${ }^{21,23,38,65,66,69}$ Other physicians stated that learning required time and effort, which could not be avoided through design. ${ }^{31}$ These physicians believed that one needs to adjust their behavior accordingly to fit the design of the e-health technology. ${ }^{31}$

\section{Facilitators}

\section{Pre-analysis of data}

Given the potential for e-health technology to generate large volumes of data, physicians would like a "pre-analysis" of the generated information. . $^{15,38,43,56}$ Pre-analysis of data would include screening and processing of raw data either electronically or by hand..$^{15,38,43}$ Physicians expressed that they would like to see an analysis of data rather than raw data. ${ }^{43}$ They would like to receive an alert after a certain number of reports are generated on the patient instead of continuously receiving alerts following every report of patient symptoms or treatment outcomes from pre-analysis in order to reduce alert fatigue. ${ }^{15,43}$ The generated data should also assist physicians in detecting adverse events, where possible. ${ }^{43}$

\section{Proof of utility}

Physicians stated that they would be more likely to utilize e-health technology if research supports its utility, ${ }^{17,20,27,30,42,54,55,57}$ mainly in reducing adverse events such as medication errors and drug interactions. ${ }^{43,47}$ One physician stated that the ability to trial the software prior to purchasing it influenced their decision to adopt the EMR system. ${ }^{36}$ As another physician stated "it will be useful if the EMR system allows my assistants to print medication labels directly off the machine and attach them to the drug bags and bottles as this can help reduce clerical and labeling errors caused by handwriting". ${ }^{27}$ Also physicians with previous experience in using e-health technology had more of a positive attitude toward e-health technology and were more positive about integrating telehealth into their practice. . $^{15,21,27,28,50,61,70,71}$

\section{Training and support}

Training and support was an important facilitator to the adoption of e-health technology. ${ }^{15-18,21,27,31,38,42,46,49,50,52-54,62,64,65,70,72,73}$ As one physician stated, "training in technical skills should be provided to my assistants in order for them to become capable of using the system, but it will be extra work for me if I need to do the training myself". ${ }^{27}$ Training would need to be tailored to the individual physician's knowledge of the e-health technology with "on-site experts" who are able to provide first-line support. ${ }^{15,24,31,62}$ In addition, follow-up training sessions were also considered important to the adoption of telemedicine. ${ }^{15,16,24,31,65,70}$ Some physicians mentioned that having organizational leadership or a champion encouraged the adoption of e-health technology. ${ }^{73}$ Other physicians 
preferred one-on-one, on-demand support during real-life situations. ${ }^{31}$ In addition, lack of information technology (IT) skills can be seen as a barrier to the utilization of e-health technology. ${ }^{24,30,31,34,41,51,52,62,65,67,71}$ As one physician said, “... I cannot type and talk and listen to patients at the same time ... so I may not use the system". Furthermore, those with innovative office staff were more likely to adopt e-health technology in their respective practices. ${ }^{74,75,76}$

\section{Ownership and size of practice}

Physicians who were partial or full owners of their practice were less likely to adopt e-health technology. ${ }^{50,73,75}$ This may be due to ownership being associated with higher levels of responsibility for day-to-day operations. ${ }^{75}$ Furthermore, with increasing size of practice, physicians were less likely to adopt e-health technology. ${ }^{77}$ Smaller and lower income practices were found to be less likely to use EMRs. ${ }^{78}$ Another study found that independent practices are less likely to adopt e-health technology when compared to group practices. ${ }^{40,49,51,71,73,76}$ The literature presents an interesting contradiction where ownership and size of practice can be either a facilitator or a barrier to adoption of e-health technology. Ownership and size of practice as a barrier or facilitator seemed to depend on the type of e-health technology; EMRs, in particular, were more likely to be used in a larger practice than solo, whereas other types of e-health technology such as email communication with patients were the opposite..$^{51,71,74,78}$

\section{Discussion and conclusion}

This scoping review identifies a number of barriers and facilitators to the adoption of e-health technology by physicians. Among these themes, threatened clinical autonomy, cost and liability issues, and training and support were the most cited. Boonstra and Broekhuis, ${ }^{79}$ Castillo et al, ${ }^{80}$ Gagnon et al, ${ }^{81}$ and Goldstein et $\mathrm{al}^{82}$ support these findings. They found that the most cited barriers to EMR adoption as financial, lack of time, and technical barriers.

Boonstra and Broekhuis ${ }^{79}$ identified these most cited barriers as "primary" barriers, given that such barriers are first to arise with the adoption process of EMR. We also found other factors that need to be addressed such as motivation to adopt e-health technology, patient-physician interaction, training and support, system factors, and threatened autonomy.

One of the main themes that became apparent was the threatened clinical autonomy. This may be due to multiple factors such as the physicians' desire to autonomously form their own clinical decisions without information provided by e-health technology, ${ }^{16}$ fear of change, ${ }^{66}$ age,${ }^{58,68}$ unwillingness to adopt, ${ }^{21,23,38,65,66,69}$ and limitation in time and effort. ${ }^{31}$ Walter and Lopez ${ }^{69}$ defined professional autonomy as "professionals" having control over the conditions, processes, procedures, or content of their work according to their own collective and, ultimately, individual judgment in the application of their profession's body of knowledge and expertise professional privacy. They found that threatened professional autonomy negatively affected perceived usefulness and the intention to use e-health technology ${ }^{69}$

The second main theme that arose was cost and liability issues associated with the adoption of e-health technology by physicians. Concerns regarding reimbursement were the most cited within this theme. Physicians were less willing to utilize e-health technology with no reimbursement initiatives present. In order to facilitate the adoption of EMR systems with "meaningful use", The American Recovery and Reinvestment Act of 2009 allocated $\sim \$ 19$ billion toward incentive payments through Medicare and Medicaid. It is estimated that by 2015 , there would have been acceleration in the adoption of EMRs due to the financial incentive payments as well as Medicare penalty associated with the failure to implement EMR.

The third main theme that arose in this study was the barriers surrounding training and support. Poor services from the vendor such as poor training and support for problems associated with the e-health technology and poor follow-up are barriers to the adoption of such devices. This is further complicated given that physicians are not technical experts and the systems are inherently complicated. In order to further facilitate the adoption of e-health technology, physicians need the technology to be tailored to the individuals' knowledge of the e-health technology. Furthermore, "on-site experts" who are able to provide first-line support were highly encouraged. Lastly, follow-up sessions were considered an important factor contributing to the adoption of e-health technology.

Addressing barriers to the implementation of e-health technology is a complex process that requires support from health services authority, insurance companies, vendors, patients, and physicians. The findings of this scoping review suggest that not all barriers are present in all practices. It is important for policy makers and hospital or practice managers to understand the specific barriers that challenge the practicing physicians and design appropriate interventions to address barriers and promote facilitating factors. This may be achieved through running in-depth interviews with the users, in this case physicians, to learn what specific barriers 
challenge the particular practice. The acquisition of this knowledge will allow for the development of a customized implementation plan.

It is important to note that some barriers to the adoption of e-health technology are not within the control of implementers. Such barriers include high cost associated with the adoption and maintenance of e-health technology. In order to overcome this barrier, government incentives may be required. ${ }^{83}$ Privacy and security concerns are also barriers that are beyond the control of implementers. In order to overcome this barrier, government action may be required to establish and implement national privacy laws. ${ }^{83}$ Many countries have developed new laws and regulations to address privacy and security concerns. For instance, in the US, the Health Insurance Portability and Accountability Act Privacy Rule protects personal health information.

It is worthy to note that some countries have implemented national initiatives to overcome barriers associated with EMRs. In Canada, the Canada Health Infoway is an initiative that exists to facilitate the adoption of EMRs across the country by addressing technical and financial barriers. In the US, the Hitech Act provides incentive payments for the adoption and use of EMRs in order to address financial barriers. In Australia, HealthConnect is a national initiative to ensure that health information is securely exchanged.

This study identified current barriers and facilitators to the adoption of e-health technology by physicians and adds to the body of literature surrounding barriers and facilitators to the adoption of e-health technology. As e-health technology becomes a priority in health care and more technologies and studies evaluating the use of these technologies emerge, it is important to update the current barriers and facilitators to their adoption and implementation. The systematic reviews included in this scoping review illustrate the need for updated information and a broader focus as most focused on EMRs and all were done in or before 2014. This scoping review also discusses implications of broad- and fine-scale barriers and facilitators, such as organizational factors, and physician characteristics, such as productivity. The identification of such barriers and facilitators is important because it allows for the implementation of a targeted strategy. Implementers need to consider physician perspectives and gain their support by addressing barriers in order to create an environment where e-health technology is adopted.

This scoping review had some limitations. Although it was attempted to develop a comprehensive search strategy, electronic health technology is a very broad topic, and it is possible some relevant studies were missed. Second, other health care professionals and the patient's perspectives were not considered although both are stakeholders in the adoption of e-health technology. Thus, articles that address technologies that are more appropriate to physicians and their patients may be emphasized here, as factors specific to other health care providers perspectives were not included. Alternately, there may be barriers that are exclusive to other health care professionals or patients that significantly hinder the adoption of such technology that were missed. Other studies have been conducted that capture the perspectives of these stakeholders that were not included in this study.

\section{Future implications}

The findings of this scoping review indicate that physicians are a diverse group of individuals faced with differing barriers and facilitators that exist within different subspecialties. Therefore, it is crucial to consider specific concerns of these subspecialties within the health care providers' umbrella when implementing new e-health technologies and encouraging use of existing e-health technologies.

Future projects should consider the tensions around the adoption and develop programs to address physician-limited resources and system barriers. For instance, providing financial payback for achieving quality improvement though IT use may increase the adoption of e-health technology. Reimbursements may be provided for publishing performance reports and the use of specific IT applications. For instance, in 2003, California initiated the "pay-for-performance" program where health plans measure and reward performance, patient satisfaction, and IT use in ambulatory care. Performance incentive programs may reward performance based on multiple clinical indices and encourage users to globally use e-health technology to achieve such gains. Alternatively, performance incentive programs may selectively promote specific IT indices.

Micromanaging clinical change should be avoided. Mandating "pop-up" reminder may be complementary for some practices and intrusive in others. Indiscriminate deadlines for full EMR use should also be avoided. Full EMR use should be achieved via stepwise approach. Basic EMR use such as prescription ordering may be expected initially. Only when basic EMR use is achieved, should incentive requirement for more advanced EMR capabilities such as decision support be required. Questions remain about the design of performance incentive programs; however, the adoption of pay-for-performance programs could positively impact the uptake of e-health technology in clinical practice. 


\section{Conclusion}

Our results illustrate that there is often great uncertainty about the costs, implementation, and consequence of e-health technology. One avenue that could mitigate this uncertainty is the development of comprehensive product comparisons of EMRs. Government funding could fund product comparisons of e-health technology and research identifying full range of financial, time, and quality outcomes of EMR-using practices. Such comparison projects will allow physicians to fully visualize the impact that the adoption of e-health technology may have on their clinical practice.

\section{Acknowledgments}

The authors would like to thank Susan Powelson, Librarian, Taylor Family Digital Library, University of Calgary, for her support and the reviewers for their critical feedback. This work was supported by Ward of the 21 st Century Research and Innovation Center (www.w21c.org), University of Calgary.

\section{Author contributions}

Chloe de Grood and Aida Raissi screened titles, abstracts, and full-text articles to be included in the review; both drafted and edited the final manuscript. Yoojin Kwon conducted and developed the search strategy and also contributed to the writing and editing of the manuscript. Maria Jose Santana developed the concept of the project, contributed to the search strategy, supported the article screening process, and also drafted and edited the manuscript.

\section{Disclosure}

The authors report no conflicts of interest in this work.

\section{References}

1. Pringle M. The computer-based record for health care: an essential technology for health care. Br J Gen Pract. 1992;359:262.

2. Bates DW, Ebell M, Gotlieb E, Zapp J, Mullins HC. A proposal for electronic medical records in US primary care. J Am Med Inform Assoc. 2003;10(1):1-10.

3. Bates DW, Cohen M, Leape LL, Overhage JM, Shabot MM, Sheridan T. Reducing the frequency of errors in medicine using information technology. J Am Med Inform Assoc. 2001;8(4):299-308.

4. Porterfield A, Engelbert K, Coustasse A. Electronic prescribing: improving the efficiency and accuracy of prescribing in the ambulatory care setting. Perspect Health Inf Manag. 2014;11(Spring):1g.

5. Kuperman GJ, Bobb A, Payne TH, et al. Medication-related clinical support in computerized provider order entry systems: a review. $\mathrm{J} \mathrm{Am}$ Med Inform Assoc. 2007;14(1):29-40.

6. Akematsu Y, Tsuji M. An empirical approach to estimating the effect of e-health on medical expenditure. J Telemed Telecare. 2010;16(4): 169-171.

7. Anderson JG, Balas EA. Computerization of primary care in the United States. Int J Med Inform. 2006;3:1-23.
8. American Recovery and Reinvestment Act (2009). US Government Publishing Office. Available from: https:/www.gpo.gov/fdsys/pkg/ BILLS-111hres168rh/pdf/BILLS-111hres168rh. Accessed September $12,2015$.

9. Santana MJ, Holroyd-Leduc J, Flemons WW, et al. The seamless transfer of care: a pilot study assessing the usability of an electronic transfer of care tool. Am J Med Qual. 2014;29(6):476-483.

10. de Grood C, Eso K, Santana MS. Physicians' experience adopting the electronic transfer of care communication tool: barriers and opportunities. J Multidiscip Healthc. 2015;8:21.

11. Lupianez-Villanueva F, Mayer MA, Torrent J. Opportunities and challenges of Web 2.0 within the health care systems: an empirical exploration. Inform Health Soc Care. 2009;34(3):117-126.

12. Ajami S, Ketabi S, Saghaeian-Nejad S, et al. Requirements and areas associated with readiness assessment of electronic health records implementation. J Health Admin. 2011;14:71-78.

13. Arksey H, O’Malley L. Scoping studies: towards a methodological framework. Int J Soc Res Methodol Theory Pract. 2005;8(1):19-32.

14. Moher D, Liberati A, Tetzlaff J, Altman DG, The PRISMA Group. Preferred reporting items for systematic reviews and meta-analyses: the PRISMA statement. PLoS Med. 2009; 6(6): e1000097.

15. Ajami S, Bagheri-Tadi T. Barriers for adopting Electronic Health Records (EHRs) by physicians. Acta Inform Med. 2013;21(2):129-134.

16. Davidson E, Simpson CR, Demiris G, Sheikh A, McKinstry B. Integrating telehealth care-generated data with the family practice electronic medical record: qualitative exploration of the views of primary care staff. J Med Res. 2013;2(2):e29.

17. Thorn SA, Carter MA, Bailey JE. Emergency physicians' perspectives on their use of health information exchange. Annu Emerg Med. 2014;63(3):329-337.

18. Putzer GJ, Park Y. Are physicians likely to adopt emerging mobile technologies? Attitudes and innovation factors affecting smartphone use in the Southeastern United States. Perspect Health Inf Manag. 2012;9(Spring):1b.

19. Straus SG, Chen AH, Yee H Jr, Kushel MB, Bell DS. Implementation of an electronic referral system for outpatient specialty care. AMIA Annu Symp Proc. 2011;2011:1337-1346.

20. Yau GL, Williams AS, Brown JB. Family physicians' perspectives on personal health records: qualitative study. Can Fam Physician. 2011; 5(5):e178-e184.

21. Steinschaden T, Petersson G, Astrand B. Physicians' attitudes towards eprescribing: a comparative web survey in Austria and Sweden. Inform Prim Care. 2009;17(4):241-248.

22. Morton E, Wiedenbeck S. A framework for predicting EHR adoption attitudes: a physician survey. Perspect Health Inf Manag. 2009; 6(Fall):1a.

23. Pizzi LT, Suh DC, Barone J, Nash DB. Factors related to physicians' adoption of electronic prescribing: results from a national survey. $\mathrm{Am}$ J Med Qual. 2005;20(1):22-32.

24. Vishwanath A, Scamurra S. Barriers to the adoption of electronic health records: using concept mapping to develop a comprehensive empirical model. Health Informatics J. 2007;13(2):119-134.

25. Greiver M, Barnsley J, Glazier RH, Moineddin R, Harvey BJ. Implementation of electronic medical records: theory-informed qualitative study. Can Fam Physician. 2011;57(10):e390-e397.

26. Muslin IS, Vardaman JM, Cornell PT. Fostering acceptance of computerized physician order entry: insights from an implementation study. Health Care Manag. 2014;33(2):165-171.

27. Dikomitis L, Green T, Macleod U. Embedding electronic decisionsupport tools for suspected cancer in primary care: a qualitative study of GPs' experiences. Prim Health Care Res Develop. 2015;16(6):548-555.

28. Brooks E, Turvey C, Augusterfer E. Provider barriers to telemental health: obstacles overcome, obstacles remaining. Telemed J E Health. 2013; 19(6):433-437

29. Iqbal U, Ho CH, Li YC, Nguyen PA, Jian WS, Wen HC. The relationship between usage intention and adoption of electronic health records at primary care clinics. Comput Methods Programs Biomed. 2013;112(3):731-737. 
30. Chen R, Hsiao J. An investigation on physicians' acceptance of hospital information systems: a case study. Int J Med Inform . 2012;81(12):810-820.

31. Dunnebeil S, Sunyaev A, Blohm I, Leimeister JM, Krcmar H. Determinants of physicians' technology acceptance for e-health in ambulatory care. Int J Med Inform. 2012;81(11):746-760.

32. Vedel I, Lapointe L, Lussier M, et al. Healthcare professionals' adoption and use of a clinical information system (CIS) in primary care: insights from the Da Vinci study. Int J Med Inform. 2012;81(2):73-87.

33. Holden R. What stands in the way of technology-mediated patient safety improvements?: a study of facilitators and barriers to physicians' use of electronic health records. J Patient Saf. 2011;7(4):193-203.

34. Hackl WO, Hoerbst A, Ammenwerth E. Why the hell do we need electronic health records? EHR acceptance among physicians in private practice in Austria: a qualitative study. Methods Inf Med. 2011;50(1):53-61.

35. Hier D, Rothschile A, LeMaistre A, Keeler J. Differing faculty and housestaff acceptance of an electronic health record. Int J Med Inform. 2005;74(7-8):657-662.

36. Perna G. Soul road: one solo doc's extensive EMR journey implementing an EMR is a long process fraught with obstacles, especially for a solo practitioner. Healthc Inform. 2013;31(3):36-38.

37. Russ AL, Zillich AJ, McManus MS, Doebbeling BN, Saleem JJ. A human factors investigation of medication alerts: barriers to prescriber decision-making and clinical workflow. AMIA Annu Symp Proc. 2009;2009:548-552.

38. Olenik K, Lehr B. Counteracting brain drain of health professionals from rural areas via teleconsultation: analysis of the barriers and success factors of teleconsultation. J Public Health. 2013;21:357-364.

39. Bradford NK, Young J, Armfield NR, Herbert A, Smith AC. Home telehealth and paediatric palliative care: clinician perceptions of what is stopping us? BMC Palliat Care. 2014;13:29.

40. Simon S, Kaushal R, Cleary P, et al. Physicians and electronic health records: a statewide survey. Arch Intern Med. 2007;167(5):507-512.

41. Valdes I, Kibbe D, Tolleson G, Kunik ME, Petersen LA. Barriers to proliferation of electronic medical records. Inform Prim Care. 2004;12(1):3-9.

42. Badran H, Pluye P, Grad R. Advantages and disadvantages of educational email alerts for family physicians: viewpoint. J Med Internet Res. 2015;17(2):e49.

43. Levine M, Richardson J, Granieri E, Reid MC. Novel telemedicine technologies in geriatric chronic non-cancer pain: primary care providers’ perspectives. Pain Med. 2014;15(2):206-213.

44. Jariwala KS, Holmes ER, Banahan BF 3rd, McCaffrey DJ 3rd. Factors that physicians find encouraging and discouraging about electronic prescribing: a quantitative study. $J$ Am Med Inform Assoc. 2013;20(e1):e39-e43.

45. Leu M, O’Connor K, Marhsall R, Price DT, Klein JD. Pediatricians use of health information technology: a national survey. Pediatrics. 2012;130(6):e1441-e1446.

46. Yan X, Liu T, Gruber L, He M, Congdon N. Attitudes of physicians, patients, and village health workers toward glaucoma and diabetic retinopathy in rural China: a focus group study. Arch Ophthalmol. 2012;130(6):761-770.

47. Rogove HJ, McArthur D, Demaerschalk BM, Vespa PM. Barriers to telemedicine: survey of current users in acute care units. Telemed $J E$ Health. 2012;18(1):48-53.

48. Moskowtiz A, Chan Y, Bruns J, Levine SR. Emergency physician and stroke specialist beliefs and expectations regarding telestroke. Stroke. 2010;41(4):805-809.

49. Stream G. Trends in adoption of electronic health records by family physicians in Washington State. Inform Prim Care. 2009;17(3): 145-152.

50. Kaushal R, Bates D, Jenter C, et al. Imminent adopters of electronic health records in ambulatory care. Inform Prim Care. 2009;17(1): $7-15$.

51. Menachemi N. Barriers to ambulatory EHR: who are 'imminent adopters' and how do they differ from other physicians? Inform Prim Care. 2006;14(2):101-108.

52. Leung GM, Yu PL, Wong IO, Johnston JM, Tin KY. Incentives and barriers that influence clinical computerization in Hong Kong: a populationbased physician survey. J Am Med Inform Assoc. 2003;10(2):201-212.
53. Kane J, Morken J, Boulger J, Crouse B, Bergeron D. Rural Minnesota family physicians' attitudes toward telemedicine. Minn Med. 1995;78(3):19-23.

54. Jamoom EW, Patel V, Furukawa MF, King J. EHR adopters vs. nonadopters: impacts of, barriers to, and federal initiatives for EHR adoption. Healthc (Amst). 2014;2(1):33-39.

55. Villalba-Mora E, Casas I, Lupiañez-Villanueva F, Maghiros I. Adoption of health information technologies by physicians for clinical practice: the Andalusian case. Int J Med Inform. 2015;84(7):477-485.

56. Davis MM, Currey JM, Howk S, et al. A qualitative study of rural primary care clinician views on remote monitoring technologies. J Rural Health. 2013;30(1):69-78

57. Sinclair C, Holloway K, Riley G, Auret K. Online mental health resources in rural Australia: clinician perceptions of acceptability. J Med Internet Res. 2013;15(9):199-208.

58. Or C, Wong K, Tong E, Sek A. Private primary care physicians' perspectives on factors affecting the adoption of electronic medical records: a qualitative pre-implementation study. Work. 2014;48(4):529-538.

59. Larsen F, Gjerdrum E, Obstfelder A, Lundvoll L. Implementing telemedicine services in northern Norway: barriers and facilitators. J Telemed Telecare. 2003;9(suppl 1):S17-S18.

60. Singh D, Spiers S, Beasley B. Characteristics of CPOE systems and obstacles to implementation that physicians believe will affect adoption. South Med J. 2011;104(6):418-421.

61. Schectman JM, Schorling JB, Nadkarni MM, Voss JD. Determinants of physician use of an ambulatory prescription expert system. Int $J$ Med Inform. 2005;74(9):711-717.

62. Terry AL, Giles G, Brown JB, Thind A, Stewart M. Adoption of electronic medical records in family practice: the providers' perspective. Fam Med. 2009;41(7):508-512.

63. Meade B, Buckley D, Boland M. What factors affect the use of electronic patient records by Irish GPs? Int J Med Inform. 2009;78(8): 551-558.

64. D'Alessandro DM, D'Alessandro MP, Galvin JR, Kash JB, Wakefield DS, Erkonen WE. Barriers to rural physician use of a digital health sciences library. Bull Med Libr Assoc. 1998;86(4):583-593.

65. Hains I, Ward R, Pearson S. Implementing a web-based oncology protocol system in Australia: evaluation of the first 3 years of operation. Intern Med J. 2012;42(1):57-64.

66. Campbell J, Harris K, Hodge R. Introducing telemedicine technology to rural physicians and settings. J Fam Pract. 2001;50(5):419-424.

67. Araújo MT, Paiva T, Jesuino JC, Magalhães M. General practitioners and neurotelemedicine. Stud Health Technol Inform. 2000;78:45-67.

68. Abdekhoda M, Ahmadi M, Gohari M, Noruzi A. The effects of organizational contextual factors on physicians' attitude toward adoption of electronic medical records. J Biomed Inform. 2015;53:174-179.

69. Walter Z, Lopez MS. Physician acceptance of information technologies: role of perceived threat to professional autonomy. Decis Support Syst. 2008;46:206-215.

70. Devine E, Williams E, Martin D, et al. Prescriber and staff perceptions of an electronic prescribing system in primary care: a qualitative assessment. BMC Med Inform Decis Mak. 2010;10:72.

71. Menachemi N, Brooks R. EHR and other IT adoption among physicians: results of a large-scale statewide analysis. J Healthc Inf Manag 2006;20(3):79-87.

72. Cheung CS, Tong EL, Cheung NT, et al. Factors associated with adoption of the electronic health record system among primary care physicians. JMIR Med Inform. 2013;1(1):e1.

73. Bramble J, Galt K, Siracuse M, et al. The relationship between physician practice characteristics and physician adoption of electronic health records. Health Care Manage Rev. 2010;35(1):55-64

74. Ancker JS, Singh MP, Thomas R, et al. Predictors of success for electronic health record implementation in small physician practices. $\mathrm{Appl}$ Clin Inform. 2013;4(1):12-24.

75. Fleurant M, Kell R, Love J, et al. Massachusetts E-health project increased physicians' ability to use registries, and signals progress toward better care. Health Aff (Millwood). 2011;30(7):1256-1264. 
76. Kralewski JE, Dowd BE, Cole-Adeniyi T, Gans D, Malakar L, Elson B. Factors influencing physician use of clinical electronic information technologies after adoption by their medical group practices. Health Care Manage Rev. 2008;33(4):361-367.

77. Pevnick J, Asch S, Adams J, et al. Adoption and use of stand-alone electronic prescribing in a health plan-sponsored initiative. Am J Manag Care. 2010;16(3):182-189.

78. Mazzolini C. EHR holdouts: why some physicians refuse to plug in. Med Econ. 2014;90(22):42.

79. Boonstra A, Broekhuis M. Barriers to the acceptance of electronic medical records by physicians from systematic review to taxonomy and interventions. BMC Health Serv Res. 2010;10:231.
80. Castillo V, Martinez-Garcia A, Pulido J. A knowledge-based taxonomy of critical factors for adopting electronic health record systems by physicians: a systematic literature review. BMC Med Inform Decis Mak. 2010; 10:60.

81. Gagnon M, Desmartis M, Labrecque M, et al. Implementation of an electronic medical record in family practice: a case study. Inform Prim Care. 2010;18(1):31-40.

82. Goldstein DH, Phelan R, Wilson R, et al. Brief review: adoption of electronic medical records to enhance acute pain management. Can $J$ Anaesth. 2014;61(2):164-179.

83. Anderson JG. Social, ethical and legal barriers to E-health. Int $J$ Med Inform. 2007;76(5-6):480-483.
Journal of Multidisciplinary Healthcare

\section{Publish your work in this journal}

The Journal of Multidisciplinary Healthcare is an international, peerreviewed open-access journal that aims to represent and publish research in healthcare areas delivered by practitioners of different disciplines. This includes studies and reviews conducted by multidisciplinary teams as well as research which evaluates the results or conduct of such teams or health- care processes in general. The journal covers a very wide range of areas and welcomes submissions from practitioners at all levels, from all over the world. The manuscript management system is completely online and includes a very quick and fair peer-review system. Visit http://www.dovepress.com/ testimonials.php to read real quotes from published authors. 